\title{
Effects of Terrorism Fears on Job Attitudes and Turnover Intentions: The Moderating Role of Job Involvement
}

\author{
Omer Farooq Malik \\ COMSATS Institute of Information Technology \\ E-mail: omer_farooq@comsats.edu.pk
}

\begin{abstract}
Based on affective events theory and previous research, a model was developed and tested to analyze the effects of terrorism fears on job attitudes (i.e. job satisfaction and affective commitment) and turnover intentions. The study is based on questionnaire data collected from 201 permanent faculty members of public sector universities in Pakistan. Partial least squares structural equation modeling was used to validate the model and found substantial support for study's hypotheses. The results show that fearing future terrorism negatively influences faculty members' job attitudes, and subsequently leads to their intent to leave. Further, job involvement and job attitudes interact to predict turnover intentions. The paper explores an important but still under-researched area of management and organizational interventions to mitigate the detrimental effects of terrorism fears.
\end{abstract}

Keywords: Workplace, Fear, Terrorism, Job attitudes, Job involvement, Turnover intentions, Pakistan.

\section{Introduction}

Terrorism has recently emerged as a prominent social problem. Terrorism can occur in all parts of the globe though most incidents occur in the Middle East, South Asia, and Africa (Enders and Sandler, 2006). Terrorist attacks produce detrimental effects that are not limited to an isolated geographic region, they are man-made and not natural disasters, and they are not the result of human error or negligence. There are rival actors intending to both cause and prevent terrorist attacks (Knemeyer et al., 2009). Also, terrorist attacks are thought to create a sense of vulnerability and fear that is more pervasive and persistent compared to other types of disasters (Ryan et al., 2003).

Individuals and workplaces targeted by terrorists are not necessarily their primary enemy but may include apolitical and innocent civilians (Inness and Barling, 2005). Nevertheless, it is usually the primary enemy from whom a response is ultimately desired (Drake, 1998). Workplaces that have been affected by acts of terrorism include: government buildings, military installations, embassies, office buildings, shopping malls, trains and subways, aircraft and airports, prisons and police stations, banks, hotels, hospitals, and educational institutions. A growing number of educational institutions have been targeted by terrorists over the past 10 years as they are less protected compared to other targets. For example, the 2004 Beslan school siege in Russia, the 2014 Peshawar school massacre in Pakistan, the 2015 Garissa University College attack in Kenya. 
Over time, institutions of higher education invest substantial resources in their employees. Employee turnover is critical from individual, organizational, and industry perspectives (Shaw et al., 1998). An instance of voluntary turnover reflects an employee's decision to terminate the employment relationship. Voluntary turnover incurs significant cost, both in terms of direct costs (replacement, recruitment and selection, training and development, operational disruption; Mobley, 1982; Staw, 1980), and also (and perhaps more importantly) in terms of indirect costs (demoralization, increased workload on stayers, diminished job satisfaction, lowered commitment; Mobley, 1982; Morrell et al., 2004), and the loss of social capital (Dess and Shaw, 2001). Research suggests that intent to leave may be used as a form of coping with increased fear by withdrawing from a threatening situation rather than an increased desire on the part of the employee to voluntarily leave the organization (Rogers and Kelloway, 1997).

The research available on the psychological response of employees to terrorism has mostly been generated following the events of $9 / 11$ and focused predominantly on industrial employees in the United States (Reade, 2009). However, not much research has been conduced to examine how employees in university settings may be affected by terrorism. Towards that end, the main objectives of the study are: (1) to examine the direct effect of fearing future terrorism on job attitudes and turnover intentions, (2) to examine the direct effect of job attitudes on turnover intentions, (3) to investigate whether job attitudes mediate the effect of fear of future terrorism on turnover intentions, and (4) to investigate whether job involvement and overall job attitude interact to predict employee turnover intentions. These issues are explored using data from a sample of faculty members of public sector universities in Islamabad (Pakistan).

The paper proceeds as follows: first, the paper reviews the literature before developing a set of hypotheses. After presenting the conceptual model the paper then explains the measures and discusses research methodology including data analysis techniques. After presenting the results, the paper proceeds with a discussion of findings and offers practical and theoretical implications.

\section{Literature Review and Research Hypotheses}

\subsection{Fear of future terrorism and overall job attitude}

In terrorism literature, there is a consensus that a major objective of the perpetrators of terrorist acts is to create fear (Bongar, 2007; Shirom et al., 2008). In the case of terrorism, research has focused almost exclusively on assessing stress reactions in response to discrete events such as the 9/11 terrorist attacks, with little attention paid to ongoing reactions and fears, and particularly how anticipating future terrorist attacks effects people functioning moving forward (Sinclair and LoCicero, 2010). For the purpose of measuring the psychological impact of fearing future terrorism, Sinclair and LoCicero (2007) developed the terrorism catastrophizing scale (TCS) that consists of three subscales: rumination, magnification, and helplessness. According to Sinclair (2010), the concept of rumination has to do with the time and energy that is utilized thinking about potential threat while those who engage in magnification show a tendency to explode the 
threat in their minds. Finally, in the context of extreme fear, helplessness sets in when people believe that there is nothing they can do to change the reality.

Judge and Kammeyer-Mueller (2012) defined attitude as "a psychological tendency that is expressed by evaluating a particular entity with some degree of favor or disfavor (e.g. job attitudes)" (p. 343). Thus, the concept of evaluation is a unifying theme in attitudes research. Defined as an attitude, job satisfaction is "a positive (or negative) evaluative judgment one makes about one's job or job situation" (Weiss, 2002, p. 175). Organizational commitment, as an attitude, reflects a psychological state linking an individual to the organization based on identification with the organization's values and goals (Meyer and Allen, 1991). In Meyer and Allen's (1991) three-dimensional reconceptualization, affective commitment is the most strongly overlapping in constitutive and operational definition with attitude (Solinger et al., 2008). Further, Hulin (1991) noted considerable theoretical overlap between overall job satisfaction and affective commitment, remarking that the only clear difference between the two is their conceptual target. The target of job satisfaction is one's job or job situation, whereas the target of affective commitment is the entire organization (Hulin, 1991; Schat and Frone). Consistent with the suggestion of Harrison et al. (2006), thus, job satisfaction and affective commitment are conceptualized as indicating an underlying overall job attitude for the purpose of this study.

Whereas there are several antecedents of attitudes (Fried, 1991; Mathieu and Zajac, 1990; Randall et al., 1999), stress is definitely a factor influencing them (Bader and Berg, 2013). For example, in a study on managers in Sri Lanka, Reade (2009) found that employee sensitivity to terrorism (i.e. proxy to gauge the stress level) was negatively correlated with job satisfaction and organizational commitment. In another study amongst managers in Sri Lanka, Reade and Lee (2012) found that employee sensitivity to external stressors was inversely related to organizational commitment. Similarly, Bader and Berg (2013) found that a high level of stress from terrorism decreased expatriate's positive work attitudes toward the organization, team, and job. Nellis (2009) noted that fear of terrorism is a powerful motivator for individuals' behaviors and attitudes. Thus, the following is derived:

H1: Fear of future terrorism has a direct negative effect on overall job attitude.

\subsection{Overall job attitude and turnover intentions}

Turnover intention is conceived of as a conscious and deliberate willfulness to leave the organization within the near future, and considered as the last part of a sequence in the withdrawal cognition process (Mobley et al., 1978), which also includes thoughts of quitting and intentions to seek out alternatives (Hom et al., 1992; Tett and Meyer, 1993), in either a passive or an active job search (Kirschenbaum and Weisberg, 1994). There is consistence evidence showing that turnover intentions are the strongest cognitive precursor of actual turnover (Tett and Meyer, 1993). The voluntary turnover of valuable employees affects organizational functioning (Staw, 1980) and, thus, should be eliminated or at least reduced to the level where the overall balance within the 
organization is not subjected to negative transformations (Carmeli and Weisberg, 2006). The Mobley model (1977) cogently explained the process of how job dissatisfaction can lead to employee turnover. Mowday et al. (1984) and Lee (1988) in their studies demonstrated that other job attitudes such as organizational commitment and job involvement can also be validly linked to employee turnover via the Mobley model when substituted for job satisfaction. There is strong evidence suggesting that job attitudes reflecting negative evaluation of the job and of the employing organization influence withdrawal cognitions (e.g. Carmeli and Weisberg, 2006; Fisher 2002; Meyer et al., 2002; Naumann et al., 2000). Therefore, the following is hypothesized:

H2: Overall job attitude has a direct negative effect on turnover intentions.

\subsection{Fear of future terrorism and turnover intentions}

The Mobley model (1977) gives recognition to the fact that for some individuals, the decision to quit may be an impulsive act rather than based on a subjectively rational decision process. Supporting this idea, Parasuraman (1982) in his study demonstrated that felt stress strongly predicted voluntary turnover, suggesting that turnover is an unpremeditated and likely impulsive behavioral response to experienced stress. Chang and Lyons (2012) found a significant positive relationship between emotional strain and turnover intentions. In the same vein, Rogers and Kelloway (1997) results showed that fearing future violence did not predict affective commitment. However, fear did predict individuals' intent to leave the organization. These findings suggest that intent to leave is a form of coping with increased fear by withdrawing from a dangerous situation rather than an increased desire to leave the organization on the part of the employee (Rogers and Kelloway, 1997; Zapf and Gross, 2001). Hence, the following is expected:

H3: Fear of future terrorism has a direct positive effect on overall job attitude.

\subsection{Mediating role of overall job attitude}

Affective Events Theory (AET) defines judgment-driven behaviors as "well considered decisions and specifically, those behaviors where the overall evaluation of the job enters into that decision." These are contrasted to affect-driven behaviors that can be "of a relatively short duration and high variability" (Weiss and Cropanzano, 1996, p. 52). Thus, according to AET, judgment-driven behaviors are mediated by attitude, whereas there is a direct relationship between affective reactions and affect-driven behaviors. AET focuses on job attitudes that are formed over time and are relatively stable, such as job satisfaction and organizational commitment (Russell and Eisenberg, 2012). In support of these ideas, Fisher (2002) found that turnover intentions were better predicted by job attitudes than by affective reactions. In addition, she showed that helping behavior was more strongly related to positive affective reactions than to job attitudes. Bader and Berg (2013) in their study found that job attitudes mediate the relationship between terrorism-induced stress and expatriate performance. Fear of future terrorism is therefore likely to change job attitudes by creating disfavor towards the organization and job. In 
turn, negative job attitudes are expected to increase employees' intention to leave the organization (Malik et al., 2014). Thus, the following is derived:

H4: Overall job attitude mediates the effect of fear of future terrorism on turnover intentions.

\subsection{Moderating role of job involvement}

Job involvement is defined as the extent to which an individual identifies psychologically with his/her job (Blau, 1985). In their conceptual model linking job involvement and organizational commitment to turnover intentions, Blau and Boal (1987) proposed that, beyond the main effects of the two job attitudes on turnover intentions, job involvement and organizational commitment would also interact in their relationships with turnover intentions. Supporting this idea, Sjöberg and Sverke (2000) found that the involvement by commitment interaction significantly predicted the variation in turnover intentions. In the same vein, Martin and Hafer (1995) found that the interaction of job involvement and organizational commitment predicts turnover intentions. Thus, the following is expected:

H5: Job involvement positively moderates the negative relationship between overall job attitude and turnover intentions. Specifically, the negative relationship between overall job attitude and turnover intentions will be weaker (stronger) when job involvement is high (low).

The study hypotheses are summarized in Fig. 1. 


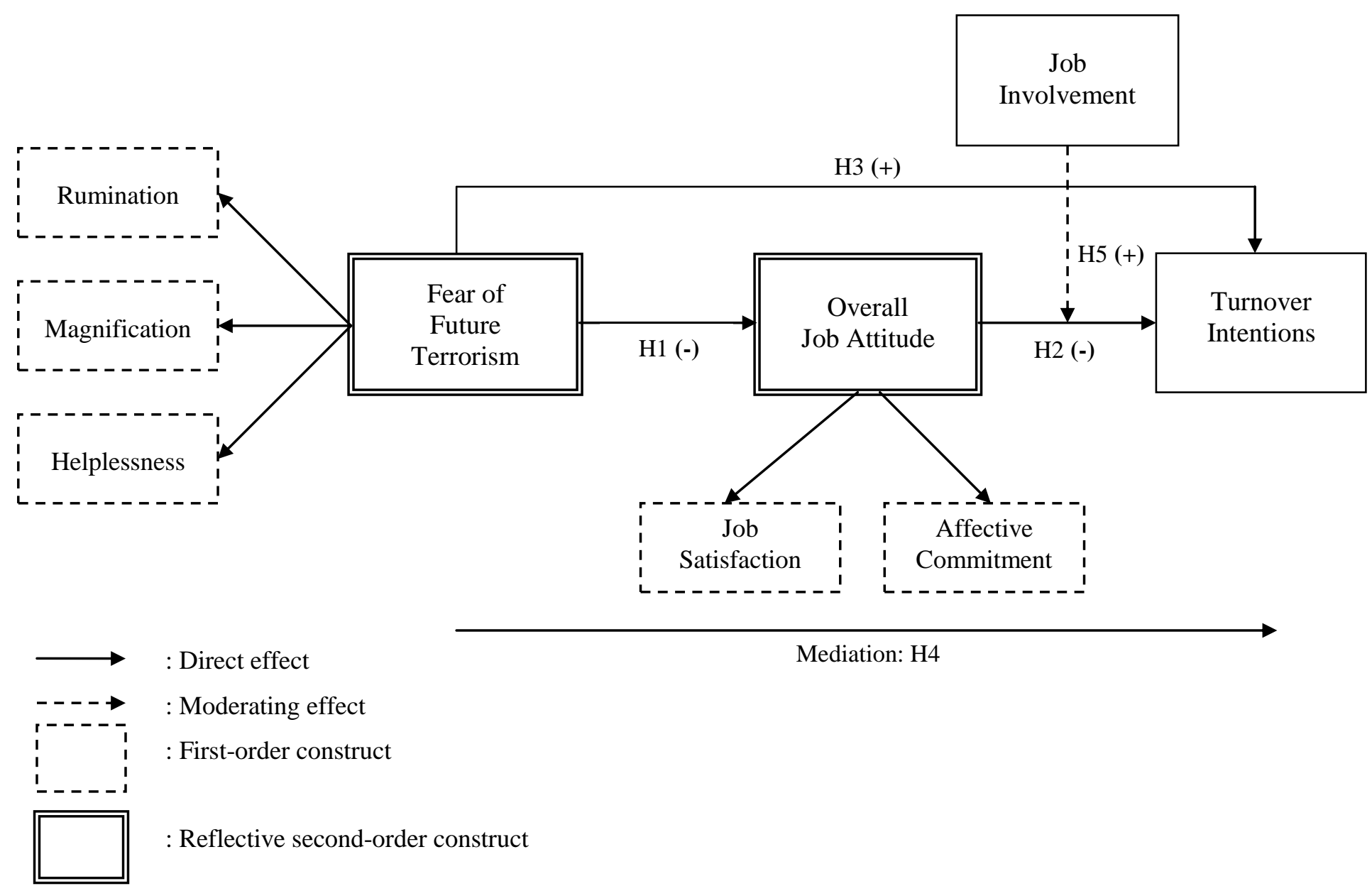

Fig. 1. Conceptual framework.

\section{Methodology}

\subsection{Research setting and sample}

In the global war on terror, Pakistan became not only the frontline fighter, but also the frontline target of terrorism. According to Political Terror Scale (PTS; Gibney et al., 2011), Pakistan is amongst the countries that are most vulnerable to terrorist attacks and terror has expanded to the whole population. The study was conducted immediately after the December 14, 2014 terrorist attack on the Army Public School in Pakistani city of Peshawar in which 132 schoolchildren were killed. All public and private educational institutions in Punjab (province of Pakistan) and Islamabad Capital Territory (ICT) were closed after the incidence owing to precarious security situation in the country. Data were collected anonymously through a self-administered questionnaire from permanent faculty members of public sector universities in ICT using convenience sampling. Of the initial 500 questionnaires sent out, retuned questionnaires numbered 216, yielding a $43 \%$ response rate, and 201 usable questionnaires. Sixty-three percent of the respondents were 
male. The average age of respondents was 34 years, and the average organizational tenure was 5 years. Respondents were well-educated, with all holding a Bachelor's degree or higher.

\subsection{Measures}

\subsubsection{Fear of future terrorism}

Fear of future terrorism was measured with 13 items from Sinclair and LoCicero's (2007) TCS comprising three subscales. Composite reliability (CR) was 0.913 for rumination, 0.954 for magnification, 0.942 for helplessness, and 0.939 for overall catastrophizing. The three subscale raw scores were transformed to standard scores based on a representative sample of adults living in the United States with a mean of 50 and standard deviation of 10. The scores can range from a low of 0 to a high of 100 . Higher scores on the scales indicate greater terrorism catastrophizing as reflected by rumination, magnification, and helplessness (Sinclair and LoCicero, 2007). For the study sample the means for rumination and magnification are about one standard deviation higher than the general population mean of 50 , while helplessness was at the population mean (see Table I).

\subsubsection{Overall job attitude}

As discussed earlier, this study specifies overall job attitude as a second-order construct, comprising two first-order reflective constructs i.e. job satisfaction and affective commitment. Job satisfaction was measured with 5 items developed by Brayfield and Rothe (1951). Affective commitment was measured with 6 items developed by Meyer et al. (1993). CR was 0.970 for job satisfaction, 0.972 for affective commitment, and 0.974 for overall job attitude.

\subsubsection{Turnover intentions}

Turnover intentions were measured with 3 items developed by Sjöberg and Sverke (2000). CR for the scale was 0.911 .

\subsubsection{Job involvement}

Job involvement was measured using 6 items from Kanungo's (1982) Job Involvement Scale. CR for the scale was 0.948 .

\section{Data Analysis}

A two-stage analytical procedure was used to analyze the data. Firstly, a confirmatory factor analysis (CFA) was conducted to assess the measurement model. Secondly, the structural model was examined. Specifically, SmartPLS 2.0 was used to conduct the analysis (Ringle et al., 2005). Bootstrapping with 201 cases and 1,000 re-samples was used to assess the path significance. The second-order constructs, fear of future terrorism 
and overall job attitude, were approximated using the repeated indicators approach (Lohmöller, 1989; Wold 1982).

Table I. Mean, standard deviation, intercorrelations of the latent variables for the first-order construct.

\begin{tabular}{|c|c|c|c|c|c|c|c|c|c|}
\hline Construct & Mean & SD & 1 & 2 & 3 & 4 & 5 & 6 & 7 \\
\hline 1. Rumination ${ }^{\mathrm{a}}$ & 59.926 & 4.231 & $0.801^{*}$ & & & & & & \\
\hline 2. Magnification ${ }^{\mathrm{a}}$ & 62.433 & 6.235 & 0.694 & $0.881^{*}$ & & & & & \\
\hline 3. Helplessness ${ }^{a}$ & 50.974 & 3.170 & 0.647 & 0.662 & $0.931^{*}$ & & & & \\
\hline $\begin{array}{l}\text { 4. Job } \\
\text { Satisfaction }^{\mathrm{b}}\end{array}$ & 3.173 & 1.304 & -0.612 & -0.573 & -0.605 & $0.935^{*}$ & & & \\
\hline $\begin{array}{l}\text { 5. Affective } \\
\text { Commitment }^{\mathrm{b}}\end{array}$ & 3.047 & 1.502 & -0.574 & -0.469 & -0.593 & 0.571 & $0.944^{*}$ & & \\
\hline $\begin{array}{l}\text { 6. Turnover } \\
\text { Intentions }\end{array}$ & 2.389 & 0.876 & 0.408 & 0.354 & 0.470 & -0.491 & -0.514 & $0.883^{*}$ & \\
\hline 7. Job Involvement & 3.023 & 0.874 & -0.296 & -0.152 & -0.397 & 0.503 & 0.487 & -0.374 & $0.858^{*}$ \\
\hline
\end{tabular}

\section{Results}

\subsection{Assessment of the measurement model}

To check the properties of the measurement scales, CFA was conducted to assess reliability, convergent validity, and discriminant validity of the scales. Most item loadings were greater than 0.7. All average variance extracted (AVEs), CRs and alpha exceeded the cut-off values of 0.5, 0.7, and 0.7, respectively (Bagozzi and Yi, 1988; Nunnally, 1978; Hulland, 1999; Hair et al., 2013). The lowest AVE (0.641) and CR (0.910) are for rumination subscale; however, these values are well-above their recommended threshold levels. Thus, convergent validity was established because all the indicators load much higher on their hypothesized construct than on other constructs (own loading are greater than cross loadings; Chin, 1998, 2010; Grégoire and Fisher, 2006). Besides, the square root of each construct's AVE is greater than its highest correlation with any other construct, thus ensuring discriminant validity (Chin, 2010, 1998; Fornell and Larcker, 1981). Consequently, the measurement model was considered satisfactory with the evidence of adequate reliability, convergent validity, and discriminant validity and was employed for assessing the structural model. 


\subsection{Assessment of the structural model}

In order to assess the structural model, the path coefficients, including an assessment of their significance, the coefficient of determination $\left(\mathrm{R}^{2}\right)$, and the Stone-Geisser $\mathrm{Q}^{2}$ (Chin, 1998; Stone, 1974; Geisser, 1975; Henseler et al., 2009; Hair et al., 2012) were examined. Overall satisfaction of the model is reflected in the coefficient of determination $\left(\mathrm{R}^{2}\right)$ of the endogenous latent variables, a common indicator in multiple regression analysis. The results of the baseline model using an inner model path weighting scheme shows a $\mathrm{R}^{2}$ of 0.271 and 0.317 for overall job attitude and turnover intentions, respectively. Blindfolding procedure (omission distance $=7$ ) to evaluate Stone-Geisser criterion revealed $\mathrm{Q}^{2}$ values greater than 0 for overall job attitude and turnover intentions, thus providing support for the model's predictive relevance (Chin, 1998; Hair et al., 2013).

\subsubsection{Path coefficients}

Results show that fear of future terrorism is negatively related to overall job attitude $(\beta=-0.521, p<0.01)$, supporting $\mathrm{H} 1$. Overall job attitude is negatively related to turnover intentions $(\beta=-0.447, p<0.01)$, supporting $\mathrm{H} 2$. Moreover, fear of future terrorism is positively related to turnover intentions $(\beta=0.147, p<0.05)$, supporting $\mathrm{H} 3$.

\subsubsection{Mediating role of overall job attitude}

The mediation hypothesis was analyzed applying the product-of-coefficients approach (Preacher and Hayes, 2008, 2004). Accordingly, the sampling distribution of 'path a' (path coefficient from fear of future terrorism to overall job attitude) and 'path b' (path coefficient from overall job attitude to turnover intentions) was bootstrapped using 1,000 re-samples. Results show that overall job attitude partially mediates the relationship between fear of future terrorism and turnover intentions $(\mathrm{a} \times \mathrm{b}=0.233 ; 95 \% \mathrm{CI}=0.148$, 0.286 ; VAF $=57 \%$ ). Thus, H4 is supported.

\subsubsection{Moderating role of job involvement}

PLS product indicator approach (Chin et al., 2003) was applied to detect the moderating effect of job involvement on the relationship between overall job attitude and turnover intentions. To test the possibility of such effect, mean-centered indicators of the predictor (overall job attitude) and the moderator (job involvement) were multiplied to create an interaction construct (overall job attitude $\times$ job involvement) to predict turnover intentions (Chin et al., 2003; Henseler and Fassott, 2010).

Following the guidelines of Chin (2010) and Chin et al. (2003), a bootstrap resembling procedure was performed to assess whether the interaction effect is significant. The results of 1,000 re-samples indicated that path coefficient of 0.201 for the interaction construct is significant at $p<0.01$ ( $t$-value $=6.174)$. As suggested by Henseler and Fassott (2010), the moderating effect was further assessed by comparing the proportion 
of variance explained (as expressed by the coefficient of determination $\mathrm{R}^{2}$ ) of the main effects model with the $\mathrm{R}^{2}$ of the interaction model (i.e. $0.332-0.317$ / 1 - 0.332).

The results showed that the size of the moderating effect is small $\left(f^{2}=0.02\right.$; Cohen 1988). Consequently, it is confirmed that job involvement moderates the relationship between overall job attitude and turnover intentions, thus supporting H5. Fig. 2 illustrates the ordinal relationship between job involvement and overall job attitude in the prediction of turnover intentions. The graph clearly demonstrates that low levels of job attitude have a stronger negative effect on employee turnover intentions in the low job involvement condition compared to employees in high job involvement condition (see Fig. 2).

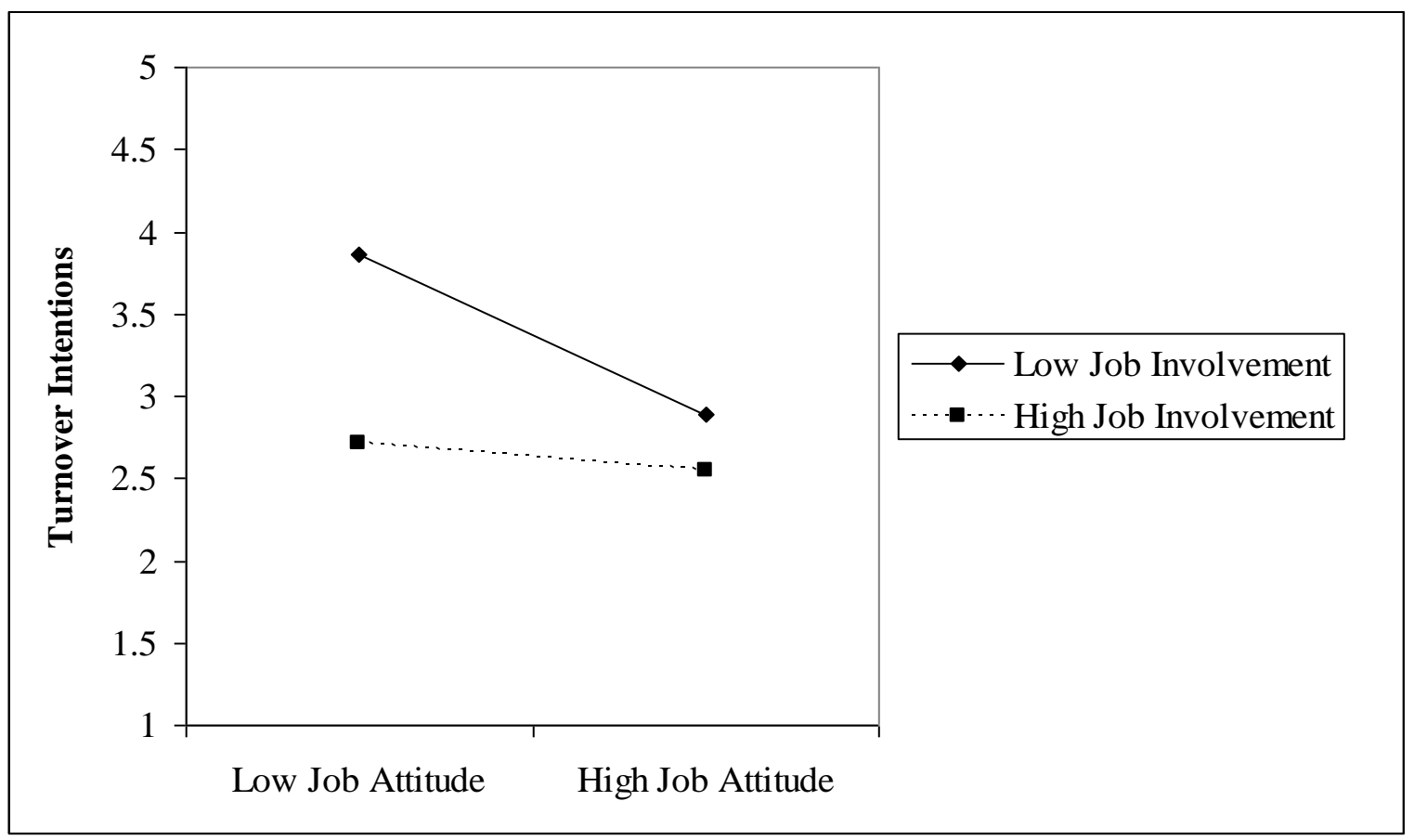

Fig. 2. Plot of the interaction between overall job attitude and job involvement in predicting turnover intentions.

\section{Discussion}

Results show that fearing future terrorism negatively and significantly predicts overall job attitude. The finding is consistent with previous research suggesting that when psychological contract of safety is unmet, employees are likely to hold the organization responsible because employees may expect that organizations can and should maintain their workplaces a safe and trusting place (e.g. Hershcovis and Barling, 2010; Howie, 2007). When trust is compromised between employees and employers; consequently, there can be reciprocity in negative attitudes toward the organization (e.g. lowered organizational commitment; Reade and Lee, 2012) and job (e.g. distancing oneself from work; Bader and Berg, 2013). By bringing the extra-organizational factors (i.e. fear of terrorism) into the employee attitudes model, the results call attention to the need for 
extending the existing models that typically assume that the level of employee job attitudes is determined by internal organizational factors.

The study found a significant negative relationship between overall job attitude and turnover intentions. This is consistent with previous research suggesting that job attitudes reflecting negative evaluation of the job and of the employing organization influence withdrawal behaviors such as intent to turnover (e.g. Bader and Berg, 2013; Naumann et al., 2000). As positive attitudes serve as a necessary predictor to desirable behaviors, it is important mangers be cognizant of the attitudes their employees hold. It behooves human resource managers to design and support programs and initiatives to help shift employee attitudes in a positive direction.

Results also show that fear of future terrorism has a direct positive effect on turnover intentions. This suggests that employees who perceive high levels of danger in their jobs are likely to report stress-related withdrawal behaviors of turnover (Grant and Wade-Benzoni, 2009). Specifically, in the case of particularly intense or long-lasting levels of death anxiety that employees find emotionally overwhelming, the outcome can be the permanent withdrawal behavior of turnover, as employees seek to protect themselves by transitioning to jobs with less exposure to mortality cues (Zaccaro and Stone, 1988).

Further, the results show that overall job attitude partially mediates the effect of fear of future violence on turnover intentions with a point estimate of 0.233. According to AET (Weiss and Cropanzano, 1996) judgment-driven behaviors such as turnover are well considered decisions and specifically, those behaviors where the overall evaluation of the job enters into that decision. Consistent with this assumption, the finding of this study suggests that fearing future terrorism is likely to change job attitudes by creating disfavor towards the organization and job itself. In turn, negative job attitudes are expected to increase employees' intent to leave.

Finally, the results show that job involvement positively moderates the negative relationship between overall job attitude and turnover intentions. The practical implication of this finding is that, if reduced turnover is a goal, organizations will generally benefit from enhancing their employees' levels of job involvement, and their attitude toward the job and organization. Interestingly, the interaction between job involvement and overall job attitude suggests that employees with low job involvement can be more positively influenced to reduce their turnover intentions by increasing their job satisfaction and affective commitment than can employees with high job involvement (Martin and Hafer, 1995). The literature proposes that job involvement, as a function of its origin in early socialization experiences (Kanungo, 1979), is more stable than job satisfaction and organizational commitment. This suggests that if job involvement is difficult to increase, then attempts to build organizational commitment and enhancing job satisfaction become more important to reduce employee turnover (Sjöberg and Sverke, 2000). 


\section{Selected References}

Bader, B. and Berg, N. (2013), "An empirical investigation of terrorism-induced stress on expatriate attitudes and performance", Journal of International Management, Vol. 19 No. 2, pp. 163-75.

Chin, W.W. (2010), "How to write up and report PLS analyses", In Vinzi, V.E., Chin, W.W. Henseler, J. and Wang, H. (Eds.), Handbook of Partial Least Squares: Concepts, Methods and Applications, Springer, Heidelberg, pp. 655-90.

Fornell, C. and Larcker, D.F. (1981), "Evaluating structural equation models with unobservable variables and measurement error', Journal of Marketing Research, Vol. 18 No. 1, pp. 39-50.

Hair, J.F., Hult, G.T.M. Ringle, C.M. and Sarstedt, M. (2013), A Primer on Partial Least Squares Structural Equation Modeling (PLS-SEM), SAGE Publications, Inc., Thousand Oaks, CA.

Hair, J.F., Ringle, C.M. and Sarstedt, M. (2011), "PLS-SEM: indeed a silver bullet", Journal of Marketing Theory and Practice, Vol. 19 No. 2, pp. 139-51.

Henseler, J. and Fassott, G. (2010), "Testing moderating effects in PLS path models: an illustration of available procedures", In Vinzi, V.E., Chin, W.W. Henseler, J. and Wang, H. (Eds.), Handbook of Partial Least Squares: Concepts, Methods and Applications, Springer, Heidelberg, pp. 713-35.

Henseler, J., Ringle, C.M. and Sinkovics, R.R. (2009), "The use of partial least squares path modeling in international marketing”, Advances in International Marketing, Vol. 20, 277-319.

Malik O.F., Abdullah, H. and Uli, J.A. (2014), "The effects of terrorism on work attitudes and behaviors: a literature review and a proposed model", Journal of Aggression, Conflict and Peace Research, Vol. 6 No. 3, pp. 143-63.

Reade, C. and Lee, H.-J. (2012), "Organizational commitment in time of war: assessing the impact and attenuation of employee sensitivity to ethnopolitical conflict", Journal of International Management, Vol. 18 No. 1, pp. 85-101.

Sjöberg, A. and Sverke, M. (2000), "The interactive effect of job involvement and organizational commitment on job turnover revisited: a note on the mediating role of turnover intention", Scandinavian Journal of Psychology, Vol. 41 No. 3, pp. 247-52.

Weiss, H.M. and Cropanzano, R. (1996), "Affective events theory: a theoretical discussion of the structure, causes and consequences of affective experiences at work", Research in Organizational Behavior, Vol. 18, pp. 1-74. 